\title{
Effect of Oxygenated Treatment to Oxide Growth and Exfoliation of Superheater Tubes
}

\author{
M.C. Zheng \\ State Grid Anhui Electric Power Corporation Research \\ Institute \\ China Anhui
}

\begin{abstract}
Based on the increasing attention of the effect on oxygenated treatment to oxide growth and exfoliation in supercritical units superheater tubes, this article introduced the mechanism of oxygen oxidation at first, and then the domestic and foreign related research in the effect on oxygenated treatment to oxide growth and exfoliation in supercritical units superheater tubes was summarized, In addition, the research directions of scale problems were discussed.
\end{abstract}

Keywords-oxide scale; oxygenated treatment; superheater tube; exfoliation

\section{INTRODUCTION}

To prevent the flow accelerated corrosion of the water supply system with OT has incomparable advantage, which is the preferred technology of water treatment in super (super) criticality pressure thermal power unit. However, researchers doubt the steam oxidation mechanism constantly in recent years, they think dissolved oxygen have an effect on the growth and exfoliation of the oxide scale, and oxygen oxidation mechanism is put forward. At present, the effect of OT to oxide growth and exfoliation of superheater tubes is not entirely clear. but large scale can be found in the superheater of the actual application of some power plants in China with the implementation of water after treatment with oxygen run soon, some even superheater pipe explosion accident happened. Therefore, it is pointed out that the study of effecting of OT to growth and exfoliation of oxide scale (there has been significant controversy) will be the direction of scale research.

\section{OXYGEN OXIDATION MECHANISM}

The core of the current view is acknowledged oxygen oxidation mechanism, the dissolved oxygen can also be contributes to the scale growth, flaking; oxygen oxidation mechanism of formula is listed for the first time in "Program on Technology Innovation: Oxide Growth and Exfoliation on Alloys Exposed to Steam" published of American EPRI in 2007[1], the formula is as follows:

$$
3 \mathrm{Fe}+2 \mathrm{O}_{2}(g)=\mathrm{Fe}_{3} \mathrm{O}_{4}
$$

$$
\mathrm{Fe}+\mathrm{O}_{2}(\text { dissolved }+ \text { dissociation }) \Leftrightarrow F e_{x} O_{y}
$$

When considering the likely corrosion behavior of alloys in steam, it is first useful to examine the types of oxide scales

\author{
S. Liu, J.F. Xiao, Z.P. Zhu \\ Changsha University of Science \& Technology \\ China Changsha
}

likely to form in the environment, as a function of metal temperature and steam pressure. In pure steam, the oxygen required to drive the oxide growth process is assumed to be generated by the dissociation of steam via:

$$
H_{2} \mathrm{O}(g) \Leftrightarrow H_{2}(g)+1 / 2 \mathrm{O}_{2}(g)
$$

The parameter that determines which oxides are likely to form is the oxygen partial pressure in the steam $\left(\mathrm{pO}_{2}\right)$, which is given by:

$$
k=p O_{2}^{0.5} \square p H_{2} / p H_{2} \mathrm{O}
$$

where $\mathrm{k}$ is the equilibrium constant for steam dissociation, which is related to the free energy of the reaction $\left(\Delta G^{\theta}\right.$, for which data on the temperature dependence are available), via:

$$
\begin{gathered}
\log k=-\Delta G^{\theta} /(2.303 \square R \square T) \\
\Delta G^{\theta}=230000-8.14 \square T \square \ln (T)+9.25 T
\end{gathered}
$$

Assuming that the dissociation goes to equilibrium at the metal-steam or metal-oxide interface (the large surface area of oxide in contact with the steam is assumed to catalyze the dissociation process) then, if partial dissociation of 1 mole steam is assumed to give $\mathrm{x}$ moles $\mathrm{H}_{2}$ and $\mathrm{x} / 2$ moles $\mathrm{O}_{2}$, then:

$$
\begin{gathered}
p \mathrm{O}_{2}=x /(2+x) \square P \\
p H_{2}=2 x /(2+x) \square P \\
p H_{2} \mathrm{O}=2(1-x) /(2+x) \square P
\end{gathered}
$$

$$
\begin{aligned}
k^{2}= & x /(2+x) \square P \square 2 /(2+x) \square P]^{2} /[2(1-x) /(2+x) \square P]^{2} \\
& =P \square x^{3} /\left[(2+x) \square(1-x)^{2}\right]
\end{aligned}
$$

where $\mathrm{x}<<1$, Equation (10) can be written:

$$
k^{2}=P \square x^{3} / 2
$$


So that:

$$
x=\left(2 \llbracket k^{2} / P\right)^{1 / 3}
$$

Hence, the oxygen partial pressure set by the equilibrium dissociation of steam, as a function of temperature (through $\mathrm{k}$ ) and total steam pressure is given by:

$$
p O_{2}=(k / 2)^{2 / 3} \square P^{2 / 3}
$$

Where an external addition of oxygen $\left(\mathrm{p}_{0}\right)$ is present in steam, if equilibrium dissociation of steam prevails, the gas partial pressures in the dissociated steam-oxygen mixture (Equation (3)) become:

$$
\begin{gathered}
p H_{2}=P \llbracket 2 x /\left(2+x+2 p_{0}\right) \\
p O_{2}=P \square(x) /\left(2+x+2 p_{0}\right) \\
p H_{2} \mathrm{O}=P \square 2(1-x)\left(2+x+2 p_{0}\right)
\end{gathered}
$$

and Equation (10) becomes:

$$
\begin{aligned}
k^{2} & =\left[P [ ( x + 2 p _ { 0 } ) / ( 2 + x + 2 p _ { 0 } ) ] \left[P\left[2 x /\left(2+x+2 p_{0}\right)\right]^{2} /\left[P \llbracket 2(1-x)\left(2+x+2 p_{0}\right)\right]^{2}\right.\right. \\
& =P \llbracket x^{2}\left(x+2 p_{0}\right) /\left[\left(2+x+2 p_{0}\right)\left[(1-x)^{2}\right]\right.
\end{aligned}
$$

This is not a simple solution. From the figure 1, we know that with the oxygen partial pressure of external addition of oxygen p0 increased, oxygen partial pressure of steam dissociated is restrained, and the total oxygen partial pressure in the system is increased, which also namely the total oxygen partial pressure with OT is more than the condition of pure steam, as considering the total oxygen partial pressure of steam is the sum of external addition oxygen partial pressure and the equilibrium dissociation of steam oxygen partial pressure, the curve of oxygen partial pressure in the steam changed with temperature and the total steam pressure is shown in figure 2 (addition dissolved oxygen respectively $0,20,200 \mathrm{ppb}$ ), which confirmed the oxygen is influential to scale.

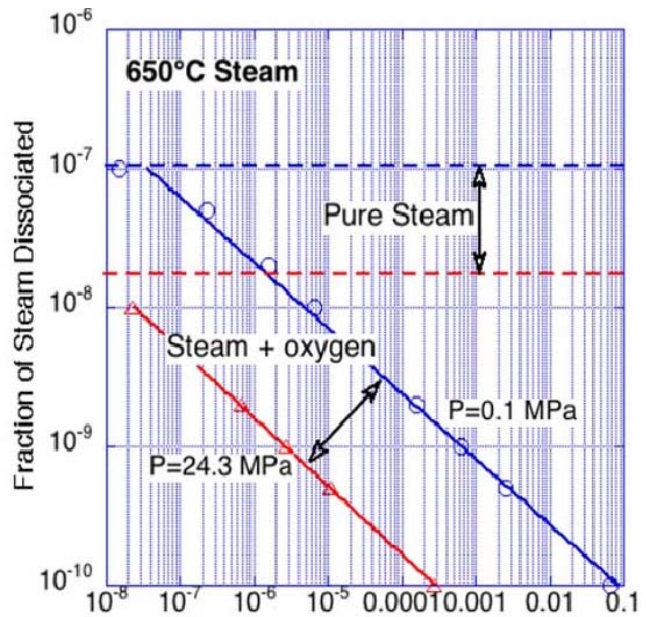

FIGURE I. OXYGEN PARTIAL PRESSURE OF STEAM DISSOCIATED IS RESTRAINED BY EXTERNAL ADDITION OF OXYGEN.

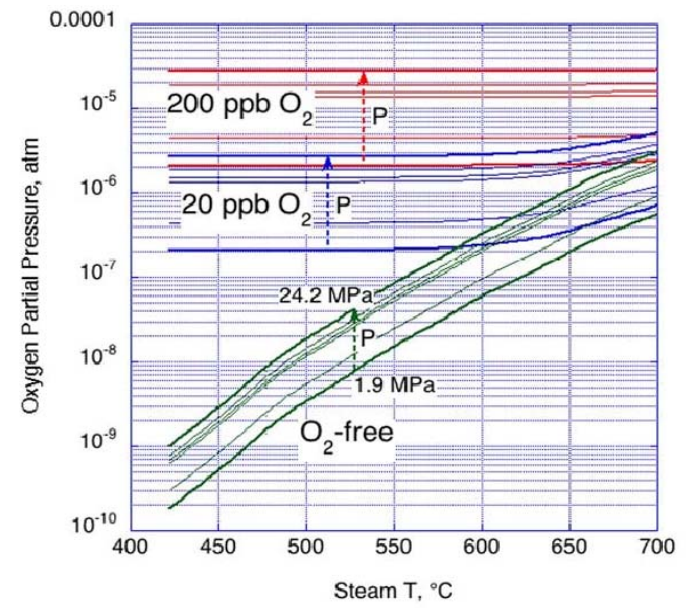

FIGURE II. THE CURVE OF OXYGEN PARTIAL PRESSURE IN THE STEAM CHANGED WITH TEMPERATURE AND THE TOTAL STEAM PRESSURE.

\section{THE RESEARCH STATUS OF DOMESTIC AND ABROAD}

\section{A. The Research Status of Abroad}

In 1929, the study of German scientist Schikorr found that the metal may occur steam oxidation in the high temperature, oxidation consumed oxygen comes from the steam dissociated rather than from the dissolved oxygen in the water. Later in the $1970 \mathrm{~s}$, scientists in Germany confirmed the facts of metal oxide generated in the reaction with iron and water vapor directly by electron microscope observation. In 1999, EPRI of the United States made studies on feed-water with oxygen treatment whether or not cause superheater pipe oxide skin peeling problems, and finally concluded that the different water conditions was less impactive on oxide skin peeling off in superheater pipe. The exfoliation of oxide scale in superheater tube is mainly due to the operation working conditions, such as temperature, pressure and material. Oak Ridge National Laboratory of the United States points out that adding oxygen partial pressure was far less than steam partial pressure, which has a little influence and can be neglected at the annual meeting of the NACE Corrosion in 2002[2]. The 
British national physical laboratory put forward that scale growth dynamics of steam chemical is not overly sensitive at the annual meeting of High - temperature Oxidation and Corrosion in 2005 [1].Oxygen oxidation mechanism of formula was listed for the first time in "Program on Technology Innovation: Oxide Growth and Exfoliation on Alloys Exposed to Steam" published of American EPRI in 2007[1]. In 2008, The British National Physical Laboratory confirmed the effect of dissolved oxygen on the growth and exfoliation of ferrite and austenite material through the experiment, especially for the influence of the austenitic steel. In 2010, ORNL also began to tend to the oxygen oxidation mechanism, which was the same with EPRI of USA [1]. Barry Dooley thought there is no effect of cycle chemistry on oxide growth and exfoliation and the use of OT does not lead to increased exfoliation of oxides and boiler tube failures at the NPL/EPRI expert workshop on oxide growth and exfoliation in January 2012.

\section{B. The Domestic Research Status}

NaiQiang Zhang etc.[3]researched about the oxidation of T92 under supercritical water $\left({ }^{\circ} \mathrm{C} / 25 \mathrm{MPa}\right)$ of different oxygen content (100 ppb, $300 \mathrm{ppb}, 2000 \mathrm{ppb})$, the results showed that the oxidation of sample quality weight increases with the increase of oxygen content in water, this is in line with the literature [62], despite the oxygen content in the water vapor is different, but the typical double-layer oxide film was formed on all the sample, including the lining of the rich chromium and ferroferric oxide of iron rich outer layer, but under the high oxygen content (2000 ppb), along with the increase of oxidation time, oxide formation and oxide on the surface of the grain size decrease and the vertical oxide block, with the increase of oxygen content in water vapor, increase the thickness of the oxide film, so the oxidation film peeling off easily.

The mechanism of Oxygenated Treatment(OT)-induced exfoliation of duplex scale in steam path can be interpreted with Ecocide Hypothesis by Hong $\mathrm{Xu}$ [4], of which the core ideas are:the inner iron/chromium-mixed oxide layer in the duplex scale reacts with high-temperature steam to form gaseous Cr-oxyhydroxides, which subsequently lead to obvious rise of cation conductivity. Cavities form at the interface of duplex scale due to reactive evaporation of $\mathrm{Cr}$ from the scale, and with the growth of cavity,the bond strength at interface drops gradually,thus the catastrophic exfoliation of duplex scale will inevitably happen. Ecocide Hypothesis may not only explain the mechanism of OT-induced exfoliation of duplex scale in steam path, but also help to predict the risk of OT. Greater risk will be created with the elongation of time duration from boiler commissioning to OT, with the rise of oxygen content in steam and with the improvement of steam parameters. To avoid the risk of exfoliation, OT should be synchronously scheduled in commissioning.

A test of adding oxygen into feed-water treatment has been carried out on one supercritical $600 \mathrm{MW}$ unit by Guangwen Zhang etc.[5]. Through measuring the growth rate of oxide skin formed in the superheater, as well as analysising the micro-structure and the variation of composition in the said oxide skin, it shows that the adding oxygen into feed-water treatment hadn't quickened the growth rate of oxide skin formed in the superheaters made from T23 and T91 steel materials, and hadn't promoted the fall-off of said oxide skin, however, in superheater made from TP347H steel, the adding oxygen into feed-water treatment boasts effect to promote the peel-off of oxide scale, whereas the process of using the above-mentioned treatment to inhibit corrosion of the superheater, the most crucial problem is to control the fall-off of oxide scale in vast amount from stainless steel tubes after using the adding oxygen treatment.

\section{PRospects}

At present, focusing on the problem OT will lead to the formation and exfoliation of the oxide scale in superheater pipe, experts are at sixes and sevens. Therefore, researching on the scale formation mechanism under the condition of OT is particularly important. Oxygen oxidation mechanism is not a simple negation and can lead to dissolved oxygen is one of the important factors affecting the scale formation. The direct environment of scale formation is water conditions, to direct and important impact on the formation of scale, then the working condition of water treatment research will be the focus and direction of the research on oxide scale in the future.

\section{REFERENCE}

[1] R B Dooley.Program on Technology Innovation:Oxide Growth and Exfoliation on Alloys Exposed to Steam[R].1013666,EPRI,2007.

[2] A.Fry, S. Osgerby, M. Wright. Oxidation of alloys in steam environments: A Review [R], NPL Report MATC(A)90, Sep. 2002.

[3] Naiqiang Zhang.Research on Oxide Scale Growth Mechanism of Boiler Tube in Power Plant Exposed to Supercritical Water with Dissolved Oxygen[D]: [dissertation]. Bao Ding:North China electric power university,2012,31-49

[4] Hong Xu. Mechanism of OT-Induced Exfoliation of Duplex Scale in Steam Path[J]. Journal of Chinese Society of Power Engineering,2011,31(9):672-677.

[5] Guangwen Zhang,Benda Sun,Jinsheng Zhang,et al.Influence of Adding Oxygen into Feed-water Treatment upon High-temperature Oxide Skin Formed in The Superheator $[\mathrm{J}]$. Thermal Power Generation, 2012,41(1):31-33. 